\title{
Enriching Online Education through Differentiated Learning
}

\author{
Montebello, Matthew; Pinheiro, Petrilson; Cope, Bill; Kalantzis, Mary; Haniya, \\ Samaa; Tzirides, Anastasia Olga; Amina, Tabassum and Searsmith, Duane.
}

University of Illinois, USA.

\begin{abstract}
Online education has been going through numerous transformations as new and innovative technologies influence and shape new e-learning portals. Differentiated e-learning promises to add value and enhance the educational services provided by an academic institution. In this paper we present our online learning model that advocates and endorses differentiated learning as an e-learning affordance that has been facilitated through the development of new learning technologies. We demonstrate how the online portal enables and supports multiple instances whereby differentiated learning is applied and practiced, including through the use of a novel analytics tool that sums up the overall learner effort in one visual.
\end{abstract}

The paper advances the notion of "productive diversity" in learning, replacing the templated sameness characterizing the communicative practices of "didactic pedagogy," including textbooks, lectures, tests. Today's computer-mediated, networked learning environments can support differentiated learning on a number of dimensions, where students are able to work at their own pace, choose their own topics within a general disciplinary rubric, and offer each other feedback in such a way that differences in perspective become a valuable resource for learning. The paper concludes by demonstrating a technology that attempts to translate these principles into practice-the CGScholar platform, including the high level progress visualizations it offers in its learning analytics.

Keywords: differentiated learning; e-learning; online portal; e-learning affordances. 


\section{Introduction}

The proliferation of e-learning at an international level is testament to the increased demand and rising awareness of education (Zhang, et al., 2004). In this respect Massive Open Online Courses (MOOCs) set a new trend to provide higher education programmes to the masses. MOOCs took the world by storm around 2012 (Matkin, 2013). These are essentially online courses that are open for all those online learners who would like to register, enrol and follow. Thousands of students typically attend such courses, making it impossible to personalise and adapt the courses to the individual needs and interests of each individual student. Amongst the numerous criticisms related to assessment, accreditation, and quality, is the impersonal nature of delivery, and this is the main motivation of our paper. It is obvious that higher education academics cannot give feedback to the individual participants of a typical MOOC keeping in mind thousands of enrolled participants. Rees (2013) argues that such online systems can never offer their students the kind of personalised education that dedicated faculty members at universities everywhere can. This could potentially be one of the reasons for dramatic decline in student retention in MOOCs (Gul, 2018), with "only about half of the students who registered ever viewed a lecture and only $4 \%$ completed a course" (Koller, Ng, Do, \& Chen, 2013).

This paper will specifically address differentiated learning as an e-learning affordance, in an effort to add value to the entire e-learning experience. Numerous online courses delivered over our e-learning portal, called Common Ground Scholar (CGScholar), purposely developed with specific design delimiters that are grounded within a reflexive pedagogical rationale. Our philosophy is based on Bloom's theoretical recommendations (Bloom, 1968) on how to aim towards mastery learning, together with an educational model of new learning affordances (Kalantzis \& Cope, 2012), made feasible through new media. One such affordance relates to differentiated learning, similar to adaptive (Shute \& ZapataRivera, 2012) and personalised learning (Conati \& Kardan, 2013) which calibrates learning to individuals (Walkington, 2012).

In this paper, we discuss how we manage to achieve differentiated learning within the online portal as learners are encouraged to express individual identities through the topical areas they choose to include, and the ways in which their senses of engagement and motivation deepen as they interact with other learners in an environment that promotes heterogeneity. In the next section we elaborate on the concept of differentiated learning, giving a broader background to our rationale, followed by a detailed description of our new learning model upon which the online portal is founded. Section 4 presents the practical aspect of how differentiated learning manifests itself within our online environment, accompanied by qualitative data analysis of survey results collected at the end of three graduate online courses held at the end of last year. Finally, we close the paper with learning conclusions and research recommendations. 


\section{Differentiated Learning}

Educational settings have always encountered learner differences, but chose to ignore, erase or remove the differences for pragmatic or ideological reasons (Kalantzis \& Cope, 2012). Nevertheless, when learners have the means to meet their needs, they are more productive. Differentiated instruction implements pedagogical techniques that adapts to the needs of the learners and try to take full advantage of their diverse abilities, interests and learning profiles (Subban, 2006). Bloom's notion of 'mastery learning' can also be supported with differentiated learning. The objective of teaching and learning is for every student to achieve mastery of a particular aspect of a domain, but they don't always have to follow the same path to achieve mastery. Formative assessment can facilitate this process, offering feedback that directs the students incrementally towards mastery objectives. Instead of retrospectively judging relative success and failure across a norm, formative assessment can tell a learner and their teacher what they still need to learn to achieve mastery. Thus, differentiated learning is most beneficial to learners who do not fit the generalized mold (Tomlinson, 2010).

Differentiated instruction is considered the way of teaching that aims to achieve success of all students, taking into account the needs of each one of them in a class (Morgan, 2014), reinforcing their responsibility and choice, peer tutoring and flexible grouping (Grimes \& Stevens, 2009). It is also very important as the diversity in student population is only increasing and so are their educational needs. Productive diversity in learning is possible with new educational media and inclusive pedagogy that incorporates learner diversity rather than being built on the one-size-fits all teaching philosophy. In today's technologyenhanced leaning environments, it is possible to engage students more deeply than was the case in traditional approaches. Students can begin learning from their own level of expertise and achieve the expected mastery at their own pace. The presence of new technological means has created a shift towards a more personalized learning (Kalantzis \& Cope, 2012; Mentis, 2007). Technological tools and media like smart phones and tablets, cloud-based computers, learning management systems, Google and many more provide the opportunity to learners to define their own learning, based on their own personal needs, to collaborate and interact with their teachers and peers and, as a consequence, to be co-designers of the learning process and content. Therefore, in today's information society, which is overwhelmed by so many technological means, we can observe a shift in the balance of agency (Kalantzis \& Cope, 2012), meaning that learners have more opportunities to participate in the learning process, be engaged and modify it according to their needs and preferences and all these become real in the spectrum of the principles of differentiated learning. 


\section{3. e-Learning Affordance}

New educational technologies have emerged since the introduction of computer-mediated and online learning. Some of these key educational technologies are related to Learning Management Systems, e-Textbooks, Flipped Classrooms. Intelligent Tutors, Games and Simulations, Discussion Boards, Web workspaces and e-Portfolios, Adaptive, Personalized and Differentiated Instruction and Machine Assessments (Cope \& Kalantzis, 2016). Yet, none of these technologies is particularly new, since shifts in educational media have been a long time coming. In fact, digital media do not necessarily change anything fundamental in schools (Cope \& Kalantzis, 2017), and some of them have already been present for quite a long time in traditional schooling contexts and not rarely have been used to replicate old teaching and learning practices (Knobel \& Lanlshear, 2007; Lankshear \& Knobel, 2008; Cope \& Kalantzis, 2013).

In a different direction, however, it is possible to use educational technologies to promote real changes in the education system from an e-learning ecologies perspective, which can impact learners' configurations of space, their relationships, the textual forms of knowledge to which they are exposed, the kinds of knowledge artefacts that they create, and the way the outcomes of their learning are measured (Cope \& Kalantzis, 2103; 2016; 2017). According to Cope and Kalantzis (2017), e-learning ecologies would be a kind of 'metaphor' to understand the learning environment as an ecosystem, consisting of the complex interaction between human, textual, discursive and spatial dynamics. These elearning ecologies are, therefore, pedagogical and epistemic forms that underlie reflexive/inclusive education (Cope and Kalantzis, 2017). In order to operationalize such elearning ecologies, Cope and Kalantzis (2013) heuristically segmented them into seven "new learning" affordances (e-Learning Affordances): ubiquitous learning, active knowledge production, multimodal knowledge representations, recursive feedback, collaborative intelligence, metacognitive reflection and differentiated learning. The authors also point out that, in the CGScholar environment, these affordances constitute an 'agenda for new learning and assessment' to reframe the relations of knowledge and learning, recalibrating traditional modes of pedagogy in order to create learning ecologies which are more appropriately attuned to our times. All the seven affordances constitute the grounds for the reflexive pedagogical rationale and the learning analytics with which CGScholar deals.

The focus of this paper is particularly on differentiated learning. "Traditional classroom communication architectures were oriented to one-size-fits-all transmission of homogeneous content" (Cope \& Kalantzis, 2013, p. 353). In this environment, the schooling system ignore or even erase students' differences, both for pragmatic reasons, which are intrinsic to the one-to-many character of educational system, and for ideological reasons, in order to enforce uniformity related to the homogenizing project of the nation- 
state (Cope and Kalantzis, 2017). Conversely, in the CGScholar environment, it is more feasible to promote a differentiated learning because, first of all, learners can work at their own pace. This means that if a "work involves research, drafting, review, revision and publication, not every student has to be up to the same stage in the process at the same stage. The teacher has an immediate view of where they are up to in the project status screen" [...]. "Moreover, positioning the student as a knowledge producer affords more space for student voice, interest, experience and localized relevance. In general terms, the intellectual project might be the same, but the topics may vary" (Cope and Kalantzis, 2013, p. 354). Therefore, rather than maintaining homogeneity, typical of a traditional classroom, CGScholar deals with the principle of productive diversity or the complementarity of differential knowledge and experiences (Cope and Kalantzis, 2013).

\section{Scholar's Case Study}

We present a case study where we embrace digital tools for differentiating students' learning. The online e-learning platform CGScholar educators have the capability to differentiate learning in many different ways. First, this platform helps to differentiate the learning content when teachers work on developing a learning module with multimodal learning elements including videos, images, audio files, charts, reports, ppt slides and plain text as to accommodate different learning styles. Secondly, CGScholar makes it possible to differentiate the process of learning in the way how students learn. It allows teachers to design multiple individual and collaborative learning activities to suit students' needs such as making posts, commenting on others' posts, peer-review assignments, collaborative writing and taking quizzes. Third, this platform also allows for differentiating the products relying on formative assessments and recursive feedback from instructors, experts, peers and even a self-review of one's own work. Lastly, the platform makes it possible for students to work at their own pace as they work through the learning content, participate in the class discussion, and do their assignments. Along the way, they are able to check their progress via the visual learning tool that we will explain below in more detail.

Scholar Analytics is a learning visualization tool, where in any unit of work a student can see their progress towards mastery, and a teacher can see the comparative progress towards mastery of all members of the class, identifying which students may require more time or special attention to achieve mastery. As students work they have access at all times to an aster plot visualization (shown in Figure 1) where each petal of the "flower" represents a type of learner activity and individual progress is displayed. At the start of a unit of work the plot is empty of colour. As learners progress in their work unit the petals grow using data continuously mined across all learning activities. The width of a petal is the weighting given by the teacher to this aspect of learning. The length of the petal shows learner 
achievement to this point. The central score, $\theta$, is the weighted average of all petals showing progress towards mastery. Petals are divided into three sectors: "Focus," $\varphi$, is "perseverance," measuring variables such as time on task and amount of work produced; $\beta$, "Help," measures community contributions and collaborations, such as the extent and quality of comments on others' posts and peer reviews; and $\varepsilon$, "Knowledge," measures knowledge via data elements such as quizzes and peer review ratings against rubrics.

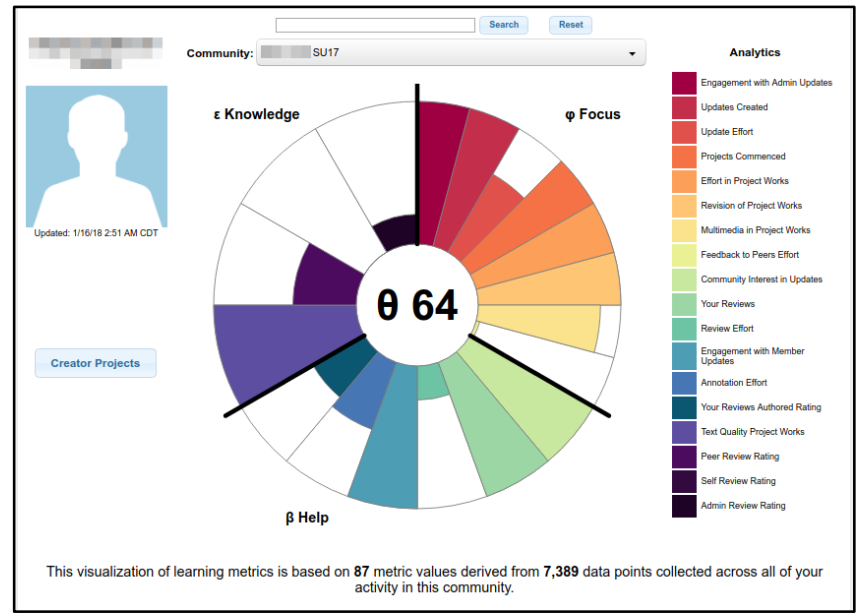

Figure 1 - Aster Plot for an individual student

The teacher can choose to include a petal or not for different units of work. Custom petals can also be added to the visualization where scores are entered manually with personalized feedback to the learner. This visualization provides differentiated learning support for students in several ways. The petals are active. When the learner places the mouse pointer over a title a score appears, and when clicked a window opens up with information about a student's performance accompanied by help text provided by the teacher, customized for the particular learning activity. At any time during the work unit a student has access to this formative feedback, a clear depiction of their progress to that point in time with guidance for improvement. The plot as a whole depicts all of the areas where additional work is needed, and as work is completed the petals grow denoting accomplishment. Each learner's plot will be different, reflecting the individual progress and the specific pace of the same student, showing how efforts have been distributed.

The plot serves as motivational device denoting progress, facilitating planning, and rewarding effort. In addition, learning activities are channelled across aspects of grit (help), knowledge, and collaboration (help), indicated by the three sectors. Individual petal scores are capped at the perimeter of the circle, meaning over-achievement in one activity is not rewarded, guiding the student's efforts to under-developed areas of the plot. At any point students can access their work data to drill down on the particulars of a petal's score such as 
peer reviews, quiz results, versions of their writing assignments, and their written collaborations with peers and teachers. Teachers also see an aster plot that averages scores over the entire class. On a separate screen there is a table breakdown of each petal's score (columns) per student (rows). During the unit of work, the teacher is able to access each student's progress visualization, including the capacity to dig deep into areas requiring additional attention by an individual learner. This makes visible deficiencies which might otherwise pass unnoticed by the teacher. As work progresses, teachers may modify the plot at any time by removing or adding petals and changing weightings to accommodate the needs of the class dynamics.

\section{Conclusion}

In this paper, we have considered the challenge of differentiating learning both theoretically and practically. In theoretical terms, differentiated learning is the achievement of comparable ends in ways which are not necessarily identical. For instance, students may work at a different pace. They may address general disciplinary objectives as outlined in a rubric, but the content or subject matter may be of their own choosing. They may become actively involved offering each other peer feedback, where the differences in perspective become a resource for learning. Here we call the difference "productive diversity" rather than the templated architecture of sameness - textbooks in which all students are on the same metaphorical page, lectures that everyone must hear together, and tests that are "standardized". In a pedagogy of productive diversity, learner differences become a valuable resource for learning. However, any such learning is logistically complex-far more complex than traditional, didactic pedagogy. One of the affordances of computer mediated, networked learning is the potential to manage this complexity. The CGScholar Analytics aster plot we have described in this paper is one such tool, designed to manage this level of complexity. Learning can be differentiated, but every learner has a running record of their own progress towards the general learning objectives determined by the teacher and the curriculum.

\section{References}

Bloom, B. (1968). Learning for mastery. UCLA - CSEIP, Evaluation Comment, 1(2), 1-12.

Conati, C., \& Kardan, S. (2013). Student Modeling: Supporting Personalized Instruction, from Problem Solving to Exploratory Open-Ended Activities. AI Magazine, 34, 13-26.

Cope, B., \& Kalantzis, M. (2013). Towards a new learning : the Scholar social knowledge workspace, in theory and practice. E-Learning and Digital Media, 10(4), 332-356. 
Cope, B., \& Kalantzis, M. (2016). New media and productive diversity in learning. In S. Barsch, \& S. Glutsch, Diversity in der LehrerInnenbildung. Münster, Germany: Waxmann.

Cope, B., \& Kalantzis, M. (2017). e-Learning Ecologies. New York, USA: Routledge.

Grimes, K. J., \& Stevens, D. (2009). Glass, bug, mud. Phi Delta Kappan 90(9), 677-680.

Gul, S. M. (2018). Massive open online courses: Hype and hope. DESIDOC Journal of Library and Information Technology, 38(1), 63-66.

Kalantzis, M., \& Cope, B. (2012). New Learning: Elements of a Science of Education. Illinois: Cambridge University Press.

Kalantzis, M., \& Cope, B. (2016). Learner Differences in Theory and Practice. Open Review of Educational Research, 3.

Knobel, M., \& Lanlshear, C. (2007). A new literacies sampler. New York, USA: Peter Lang Publishing, Inc.

Koller, D., Ng, A., Do, C., \& Chen, Z. (2013). Retention and intention in Massive open online Courses. Educase Review, 62-63.

Lankshear, C., \& Knobel, M. (2008). Digital literacies: concepts, policies and practices. New York: Peter Lang Publ. Inc.

Matkin, G. (2013). Massive Open Online Courses: Looking Ahead by Looking Back. Continuing Higher Education Review, 77, 49-56.

Mentis, M. (2007). Different Technologies for Differentiated Education: Social Networks, Identity and Diversity in e-Learning. The International Journal of Diversity in Organisations, Communities and Nations, 7(3), 86-93.

Morgan, H. (2014). Maximizing Student Success with Differentiated Learning. The Clearing House: A Journal of Educational Strategies, Issues and Ideas, 87(1), 34-38.

Rees, J. (2013). The MOOC Racket. Retrieved March 12, 2014, from Future Tense: http://www.slate.com/articles/technology/future_tense/2013/07/moocs_could_be_disast rous_for_students_and_professors.html

Shute, V., \& Zapata-Rivera, D. (2012). Adaptive Educational Systems. In P. Durlach, \& A. (. Lesgold, Adaptive Technologies for Training and Education. New York: Cambridge University Press.

Subban, P. (2006). Differentiated instruction: A research basis. International Education Journal, 7(7), 935-947.

Tomlinson, C. (2010). One kid at a time. Educational Leadership 67(5), 12-16.

Walkington, C. (2012). Using Adaptive Learning Technologies to Personalize Instruction to Student Interests: The Impact of Relevant Contexts on Performance and Learning Outcomes. Journal of Educational Psychology, 105, 932-45. 